\title{
Randomized Controlled Trial
}

\section{e Intrathecal Lentivirus-mediated Transfer of Interleukin-10 Attenuates Chronic Constriction Injury-induced Neuropathic Pain through Modulation of Spinal High-mobility Group Box 1 in Rats}

Zhenghua He, MD, Qulian Guo, MD, Muzhang Xiao, MD, Chunli He, MD, and Wangyuan Zou, MD, PhD

\footnotetext{
From: Department of Anesthesiology Xiangya Hospital, Central South University, China

Address Correspondence: Wangyuan Zou, MD, PhD Department of Anesthesiology Xiangya Hospital

Central South University 87 Xiangya Road, Changsha, 410008 China

E-mail: zwyfeng@yahoo.com.cn

Disclaimer: There was no external funding in the preparation of this manuscript. Conflict of interest: Each author certifies that he or she, or a member of his or her immediate

family, has no commercial association, (i.e., consultancies, stock ownership, equity interest, patent/licensing arrangements, etc.) that might post a conflict of interest in connection with the submitted manuscript.

Manuscript received: 01-05-2013 Revised manuscript received: 03-16-2013

Accepted for publication: 04-08-2013

Free full manuscript: www.painphysicianjournal.com
}

Background: Neuropathic pain is a complex state of chronic pain that is usually accompanied by peripheral and central nervous system damage or dysfunction. Previous studies have indicated that neuroinflammation in the spinal cord is an important contributor to neuropathological and behavioral abnormalities. A series of early inflammatory markers, such as IL-1, TNF- $\alpha$, and IFN- $\gamma$, and advanced inflammatory markers, such as high-mobility group box 1 (HMGB1), are involved in neuroinflammation.

Study Design: A randomized, double blind, controlled animal trial.

Objective: In this study, a lentivirus delivering human IL-10 (LV/hIL-10) was administered intrathecally to determine the effects of IL-10 on allodynia and hyperalgesia in a chronic constriction injury-induced $(\mathrm{CCl})$ rat model of neuropathic pain.

Methods: Sprague-Dawley rats weighting 260 - 320 g were randomly divided into 4 groups. Group Sham (Sham), Group CCI \pm Normal Saline (NS), Group CCI \pm LV/hIL-10 (LV/hIL-10), and Group $\mathrm{CCl} \pm \mathrm{LV} /$ control (vector). Rats in each group were intrathecally administered NS, LV/control, or recombinant vector LV/hIL-10 in a total volume of $10 \mu \mathrm{l}$. Paw withdrawal mechanical thresholds (PWMT) and paw withdrawal thermal latency PWTL were measured one day before $\mathrm{CCI}$ (baseline) and $0,3,7,14$, and 28 days after intrathecal administration. Cerebrospinal fluid (CSF) samples were collected during surgical plane anesthesia and the collected CSF samples were used to assay for human IL-10, rat IL-1 $\beta$, rat IL-6, and rat TNF- $\alpha$ by enzyme-linked immunosorbent assay (ELISA). Animals were sacrificed and the L4-5 lumbar segment of the spinal cord was removed for determination of green fluorescent protein (GFP) expression. Immunohistochemical analysis was performed using anti HMGB1 antibodies and the expression of HMGB1 protein in the spinal cord was determined by Western blot analysis after intrathecal delivery ( $n=8$ each).

Results: The results show that intrathecal LV/hIL-10 reverses enhanced pain states. Moreover, the increased level of HMGB1 exhibited in a late stage of $\mathrm{CCl}$ was inhibited by exogenous overexpression of hIL-10 in the CCI model. Expression of HMGB1, RAGE, and pAkt were lower in $\mathrm{CCl}$-induced rats treated with LV/hIL-10 than in those treated with LV/control (vector) or saline (NS). Our results showed that IL-10 inhibits activation of the inflammatory HMGB1-RAGE pathway in the $\mathrm{CCl}$ rat model.

Limitations: Further experimental investigations are needed to clarify the specific biological roles played by HMGB1 in IL-10-mediated regulation of neuropathic pain.

Conclusion: Our results indicate that intrathecal lentiviral-mediated transfer of IL-10 attenuates $\mathrm{CCl}$-induced neuropathic pain in rats. The anti-thermal hyperalgesia and anti-mechanical allodynia may be partly attributable to the decreased expression of HMGB1 and inhibition of HMGB1-RAGE pathway.

Key words: Analgesia, interleukin-10, lentiviral, HMGB1, intrathecal, randomized, controlled trial

Pain Physician 2013; 16:E615-E625 
$\mathbf{N}$ europathic pain is a refractory chronic pain syndrome with a complicated mechanism, and effective therapy has yet to be developed $(1,2)$. Spinal cord glias are considered critical to the creation and maintenance of pain through the release of proinflammatory cytokines (3-5). An intimate relationship has been documented between neuropathic pain and high levels of expression of early inflammatory cytokines like IL-6, TNF- $\alpha$, and IL-1 $\beta$ (6-8). However, anti-inflammatory cytokines such as interleukin-10 (IL-10) can suppress these proinflammatory cytokines. In a previous study, we reported that IL-10 overexpression attenuated TNF- $\alpha$ and IL-1 $\beta$ levels, which had been increased by lipopolysaccharides (LPS) in astrocytes (9). Recent evidence suggests that IL-10 has a notable therapeutic effect on rat neuropathic pain induced by spinal cord injury, chronic sciatic nerve constriction injury, and intrathecal administration of the HIV-1 envelope protein $(5,10-14)$.

Because anti-inflammatory cytokine IL-10 has a very short half-life (about $2 \mathrm{~h}$ ) in rat cerebrospinal fluid (CSF) (15), IL-10 gene therapy may provide a more efficient means of attaining neuropathic pain control. Milligan et al $(16,17)$ used adenovirus-vectormediated IL-10 to control neuropathic pain. Milligan et al's $(16,17)$ results suggest that intrathecal IL-10 gene therapy may provide a novel approach to prolonged clinical pain control. Lentiviral (LV) vectors are among the most popular vectors used for gene delivery into the central nervous system (CNS) (18-20). Because LV vectors can transduce a wide array of cells including non-proliferating cells, which are ubiquitous within the CNS (21), support long-term gene expression, and be modified to enhance cell targeting, they are a powerful modality to deliver life-long therapeutic proteins (22). In the previous study, we have developed a highly efficient method of LV-mediated delivery of short-hairpin RNAs (shRNA) targeting protein kinase C gamma (PKC $\gamma$ ) for in vivo gene silencing in the spinal cord of rats $(23,24)$. M.E. van Strien et al $(25)$ reported that LV-mediated overexpression of IL-10 or IL-1 receptor antagonist in rat glial cells and macrophages produced an anti-inflammatory effect.

High mobility group box 1 (HMGB1) protein is both a nuclear factor and a secreted protein. It plays a role in chronic inflammation. It is synthesized and secreted into the dorsal root ganglion (DRG) and spinal nerve, and it contributes to the development of neuropathic pain after nerve injury $(9,26-28)$. One of our previous studies indicated that the expression of HMGB1 decreased markedly after intrathecal injection of the TLR4 inhibitor EGCG (1 mg/kg), which was administered once daily starting one day before $\mathrm{CCl}$ surgery and continuing for 3 days after. IL-10 levels in the spinal cord increased significantly. This was accompanied by dramatic improvement in pain behaviors in $\mathrm{CCl}$ rats (29). The persistent release of HMGB1 was found to contribute to tactile hyperalgesia in a rodent model of neuropathic pain (9). Milligan et al $(30,31)$ reported that the anti-inflammatory cytokine IL-10 can suppress proinflammatory cytokines such as TNF- $\alpha$, IL-1 $\beta$, IL-6, and spinal cord glial amplification of pain.

However, it remains unclear whether LV-mediated transfer of IL-10 attenuates CCl-induced neuropathic pain through modulation of spinal HMGB1 in rats. In this study, we report that HMGB1 was upregulated in a rat model of $\mathrm{CCl}$ and was inhibited by intrathecal administration of LV-mediated transfer of IL-10.

\section{Methods}

\section{Animals and Surgery}

The experiments were carried out on male Sprague-Dawley rats weighing about $260-320 \mathrm{~g}$ at the time of surgery. All surgical procedures were performed under aseptic conditions and deep anesthesia induced by a xylazine and ketamine cocktail that was injected intraperitoneally (xylazine $1.6 \mathrm{mg} /$ $\mathrm{kg}$; ketamine $64 \mathrm{mg} / \mathrm{kg}$ ). Animals were kept at room temperature and their normal circadian rhythms were maintained. They were protected from light and noise stimulation, took food and water freely, and were fed separately after surgery. Using the method described by Bennett and Xie (32), the CCI model was created at the mid-thigh level of the left hind leg. Four sterile, absorbable surgical chromic gut sutures (cuticular 4-0,

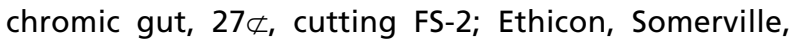
NJ, U.S.) were loosely tied around the gently isolated sciatic nerve while the rats were under anesthesia. The left sciatic nerve was exposed, but no ligature was applied to the groups of sham-operated rats. Penicillin at 40,000 unit i.m. per rat was given after surgery to prevent infection. All animal experimental procedures conformed to the guidelines established by the Council of the China Physiologic Society and were approved by the Administrative Committee of Experimental Animal Care and Use of Central South University. The study adhered to the Ethical Guidelines of the International Association for the Study of Pain (33). 
Lentiviral Vectors Expressing hIL10 (LV/hIL10)

PCYIL-10 plasmid containing the human IL-10 (hIL$10)$ coding sequence (CDS) was a kind gift from Dr. Xianmin Meng of Thomas Jefferson University (Philadelphia, PA, U.S.). LV vector (pWPXL-GFP), packaging plasmid (psPAX2), and envelope plasmid (pMD2.G) were given to us by Professor Didier Trono of the School of Life Sciences, Ecole Polytechnique Fédérale de Lausanne [EPFL] (Lausanne, Switzerland). The CDNA of hIL-10 was digested by the restriction enzymes (Pmel, Takara), which were subcloned to the LV vector backbone plasmid pWPXL-GFP. The newly generated pWPXL-hIL-10 and 2 other helper vector plasmids, psPAX2 and pMD2.G, were transfected into 293FT cells with Lipofectamine 2000 (Invitrogen). The proportion of Lipofectamine to plasmid was 2.5:1. Supernatants were harvested starting at 24 hours post-transfection every day for a total of 4 days, and centrifuged at $15,000 \mathrm{rpm} / \mathrm{min}$ for $10 \mathrm{~min}$ to remove debris. They were then transferred into a $36 \mathrm{~mL}$ ultracentrifuge tube for ultracentrifugation at $25,000 \mathrm{rpm} / \mathrm{min}$ for 3 hours. The pellet containing LV vectors was resuspended in a neural stem cell (NSC)culture medium, and aliquots were stored at $-80^{\circ} \mathrm{C}$. Viral vector titers were assayed by infection of 293FT cells at different dilutions; the titers were $1 \times 109 \mathrm{TU} / \mathrm{mL}$ after concentration by ultracentrifugation. LV vector-only expressing green fluorescent protein (GFP) was used as negative control.

\section{Intrathecal Catheter Implantation}

Lumbosacral intrathecal catheters were constructed and implanted using a lumbar approach and anesthesia as described by Malkmus and Yaksh (34). The indwelling catheters were used to microinject LV/hIL-10, LV/control vector or normal saline (NS) into the subarachnoid space surrounding the lumbar enlargement of the spinal cord. All intrathecal microinjections were performed using a $10 \mu \mathrm{L}$ volume to ensure complete drug delivery. All catheter placements were verified after death by visual inspection. Only data from animals with catheters whose tips had entered the CSF space at the lumbar enlargement of the spinal cord were analyzed.

\section{Measurement of Pain Threshold}

The thermal nociceptive threshold (PWTL) was detected using a Hargreaves apparatus (Plantar test, 7370, Ugo Basile, Comerio, Italy) as described previously (35). Rats were placed in clear plastic cages on an elevated glass plate and allowed to acclimate to their surroundings for $30 \mathrm{~min}$ before testing. After acclimation, a radiant heat source of constant intensity was placed underneath the glass and aimed at the mid-plantar area. A digital timer automatically read the duration between the start of stimuli and paw withdrawal. The PWTL was measured to the nearest $0.1 \mathrm{~s}$. The baseline PWTL of rats was controlled at about $11 \mathrm{~s}$ by adjusting the intensity of the light of the pain threshold detector. A cutoff time of $15 \mathrm{~s}$ of irradiation was used to avoid any tissue damage. Five minutes was allowed to elapse between stimulations.

Paw withdrawal mechanical thresholds (PMWT) were determined in response to pressure from an electronic von Frey anesthesiometer (2390 series, IITC Instruments, Woodland Hills, U.S.) as described previously (36). The amount of pressure (g) needed to produce a paw withdrawal response was measured 3 times on each paw at $3 \mathrm{~min}$ intervals. The results of 3 tests per each paw per day were averaged. PMWT and PWTL were measured one day before $\mathrm{CCl}$ (baseline) and 0,3 , 7,14 , and 28 days after IT administration.

\section{Western Blotting}

The rats were euthanized and the effects of LV/ hIL-10 on HMGB1 expression in the lumber spinal cord were evaluated. All rats were euthanized quickly, and the lumbar spinal cords were removed and frozen on dry ice. The dissected spinal dorsal horns were homogenized in a sodium dodecyl sulfate (SDS) sample buffer with a mixture of proteinase inhibitors (sigma).

The electrophoresis samples were heated to $100^{\circ} \mathrm{C}$ with standard Laemmli solutions for 5 minutes and loaded onto $10 \%$ SDS-polyacrylamide gels. The proteins were transferred onto a polyvinylidene difluoride membrane (PVDF, Millipore, U.S.), blocked with 5\% non-fat dry milk for one hour, and incubated overnight with primary antibodies (rabbit anti-HMGB1, 1:1000, BD Pharmigen; mouse anti-GAPDH, 1:10000, Sigma; rabbit anti-pAkt, 1:1000, anti-Akt, 1:1000, Cell Signaling Technology; rabbit anti-RAGE, 1:1000, Abcam). After incubation with horseradish peroxidase (HRP)conjugated secondary antibody (1:10,000; Amersham Pharmacia Biotech Inc., U.S.), the proteins were detected by enhanced chemiluminescence (ECL) (Amersham). The densities of the protein blots were analyzed using ImageJ software (US National Institutes of Health NIH, Bethesda, MD, http://rsb.info.nih.gov/ij).

\section{Immunohistochemical Staining and GFP Fluorescence Observation}

Spinal cords were carefully excised from the lumbar region. After fixing with $4 \%$ paraformaldehyde/ 


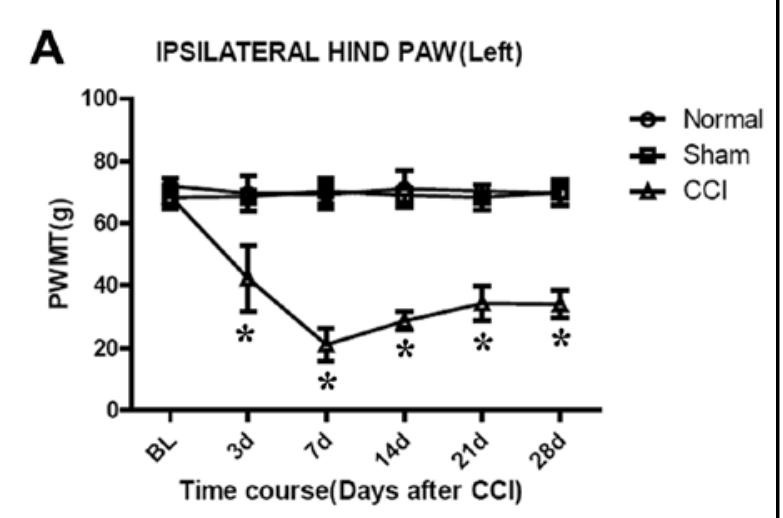

B IPSILATERAL HIND PAW(Left)

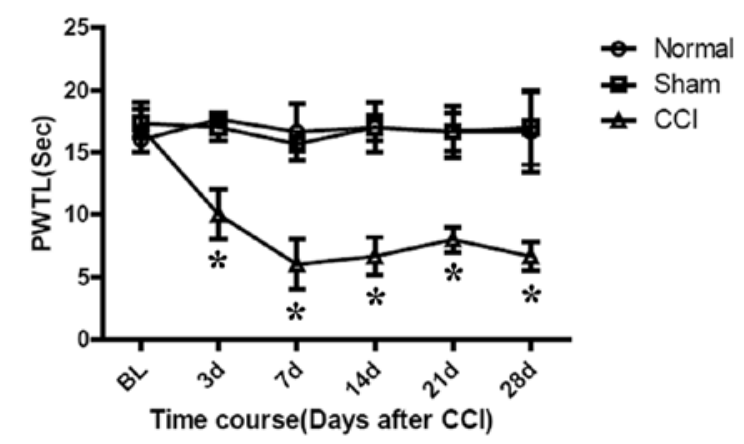

\section{CONTRALATERAL HindPaW(Right)}

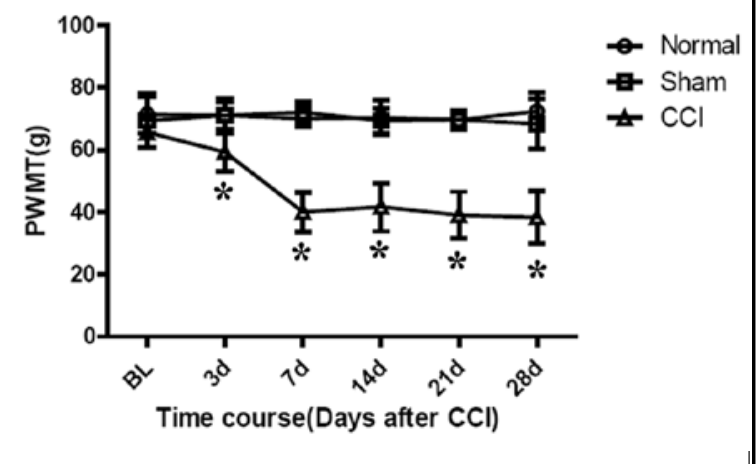

Fig. 1. CCI-induced mechanical allodynia and thermal hyperalgesia over time. CCI produced significant mechanical allodynia and thermal hyperalgesia, but normal (no surgery) and sham treatment did not. PWMT and PWTL over time are presented in Figs. $1 A$ and $B$, respectively. (C) Contralateral allodynia was observed in the CCI group. Results are presented as mean $\pm S D$ at different times following surgery. Significance is defined as ${ }^{*} P<$ 0.05 compared to the normal or sham groups at each point in time $(P<0.05)$ (8 animals per group).
PBS (Sigma) and dehydrating in 70\% ethanol, the fixed tissues were infiltrated in $30 \%$ sucrose in PBS at $4^{\circ} \mathrm{C}$ overnight. Transverse sections of the lumbar spinal cord were cut using a Leica CM1900 cryostat (Leica, Germany), and immunohistochemical analysis was performed using anti HMGB1 antibodies. The controls were routinely performed using incubation with rabbit IgG. Finally, slides were covered with Vectashield Mounting Medium (37) (Vector Laboratories, Inc, Burlingame, CA) containing $1 \mu \mathrm{M}$ DAPI (Sigma). The GFP fluorescence in the spinal cord cells was monitored with a fluorescent microscope (Leica, Germany).

\section{Enzyme-linked Immunosorbent Assay (ELISA)}

The rats were subjected to sodium pentobarbital overdose immediately upon the completion of behavioral testing. CSF samples were collected during surgical plane anesthesia. Subarachnoid space CSF samples were collected and flash-frozen in liquid nitrogen or at $-80^{\circ} \mathrm{C}$ until analyzed. Commercial Human Interleukin 10 ELISA kits (R\&D Systems) were used to assay for human IL-10, rat IL-1 $\beta$, rat IL- 6 , and rat TNF- $\alpha$, as described by the manufacturer (ELx800uv; Bio Tek Instruments, USA).

\section{Statistical Analysis}

Data are presented as mean \pm standard deviation (SD) of the indicated number of separate experiments. All statistical comparisons were computed using SPSS 15.0. Time-course measures for each behavioral test were analyzed by repeated-measures of ANOVAs followed by Student-Newman-Keuls post hoc analysis, where appropriate. The IL-10, IL-1 $\beta$, IL- 6 , and TNF- $\alpha$ contents of CSF were analyzed by one-way or two-way ANOVAs with Student-Newman-Keuls post hoc analysis. Differences were deemed significant at $P<0.05$.

\section{Results}

\section{Behavioral Assessment}

To evaluate mechanical allodynia and thermal hyperalgesia, PWMT and PWTL were determined using an electronic von Frey anesthesiometer and Hargreaves test, respectively, which were also used for video analysis 3, 7, 14, 21, and 28 days after surgery. As shown in Fig. 1, the results demonstrated significantly enhanced mechanical allodynia (F1, $20=769.8, P<0.0001)$ and thermal hyperalgesia $(F 1,20=106.2, P=0.0005)$ of the ipsilateral hindpaw in experimental groups but not in the sham group. This reached a maximum at day 7 and showed signs of amelioration on day 28. $\mathrm{CCl}$ also caused 
contralateral allodynia $(F 1,20=118.9, P=0.0004)$. Rats who received sham surgeries and those who were not operated upon displayed no significant changes from baseline with respect to mechanical allodynia (F1, $20=$ 3.723, $P=0.1259)$, thermal hyperalgesia of the ipsilateral hindpaw $(\mathrm{F} 1,20=2.408, P=0.8859)$, or contralateral allodynia (F1, $20=0.2911, P=0.6182)$ (Fig. 1).

\section{Transduction of Lentiviruses Containing GFP in Vivo}

To confirm the delivery of LV/hIL-10 into nerve cells in the spinal cord, the uptake of labeled GFP in spinal cord cells was evaluated by fluorescence microscopy. Many cell bodies were highly fluorescent after intrathecal administration of LV/hIL-10 or LV/control vector. Fluorescence was observed primarily in the cytoplasm (Fig. 2A, B).

\section{Effects of Intrathecal Administration of LVI hIL-10 on the Concentration of hIL-10 in the Spinal Cords of Rats Subjected to CCI}

To determine whether intrathecal administration of LV/hIL-10 changes IL-10 protein content in CSF, the expression of hIL10 was detected by ELISA in the CSF of rats after administration of LV/hIL10 or LV/control. The concentration of hIL10 increased significantly after 3 days $(1.68 \pm 0.39 \mathrm{ng} / \mathrm{mL})$ and 7 days $(6.15 \pm 2.66 \mathrm{ng} / \mathrm{mL})$ of administration of LV/hIL10 (F1, $30=73.64, P=0.0001)$ but not after administration of LV/control (Fig. 3A).

\section{Effects of Intrathecal Administration of LVI hIL-10 on the Release of Proinflammatory Factors in the Spinal Cords of Rats Subjected to $\mathrm{CCl}$}

To determine the effects of LV/hIL-10 on spinal cord levels of proinflammatory cytokines, the expression profiles of TNF- $\alpha$, IL- $1 \beta$, and IL- 6 were evaluated in LV/hIL-10 and LV/control after $\mathrm{CCl}$ and compared. As in other reports, TNF- $\alpha$, IL-1 $\beta$, and IL- 6 levels were increased in the lumbar spinal cord of rats after 3 days of $\mathrm{CCl}(13,25)$. Significant decreases in TNF- $\alpha(F 1,40=$ 45.66, $P<0.0001)$, IL-1 $\beta(\mathrm{F} 1,40=37.77, P=0.0003)$, and IL-6 (F1, $40=9.099, P=0.0166)$ were observed after LV/ hIL-10 administration (Fig. 3B, 3C, and 3D). Decreased TNF- $\alpha(P<0.01)$ and IL-6 $(P<0.05)$ were found 3 days after intrathecal administration of LV/hIL-10. However, IL-1 $\beta$ did not decrease until 7 days later, when the expression of HMGB1 began to increase (Fig. $3 C$ and Fig. 4A).

\section{Effects of Intrathecal Administration of LVI hIL-10 on CCl-induced Mechanical Allodynia and Thermal Hyperalgesia}

Several previous studies have shown that other methods of delivering IL10 can reverse thermal hyperalgesia and mechanical allodynia in $\mathrm{CCl}$ rats $(12,13,38)$. We also determined the effects in $\mathrm{CCl}$ rats by using $\mathrm{LV} / \mathrm{hIL}-10$. The results also showed that LV/hIL-10 successfully decreased not only $\mathrm{CCl}$-induced mechanical

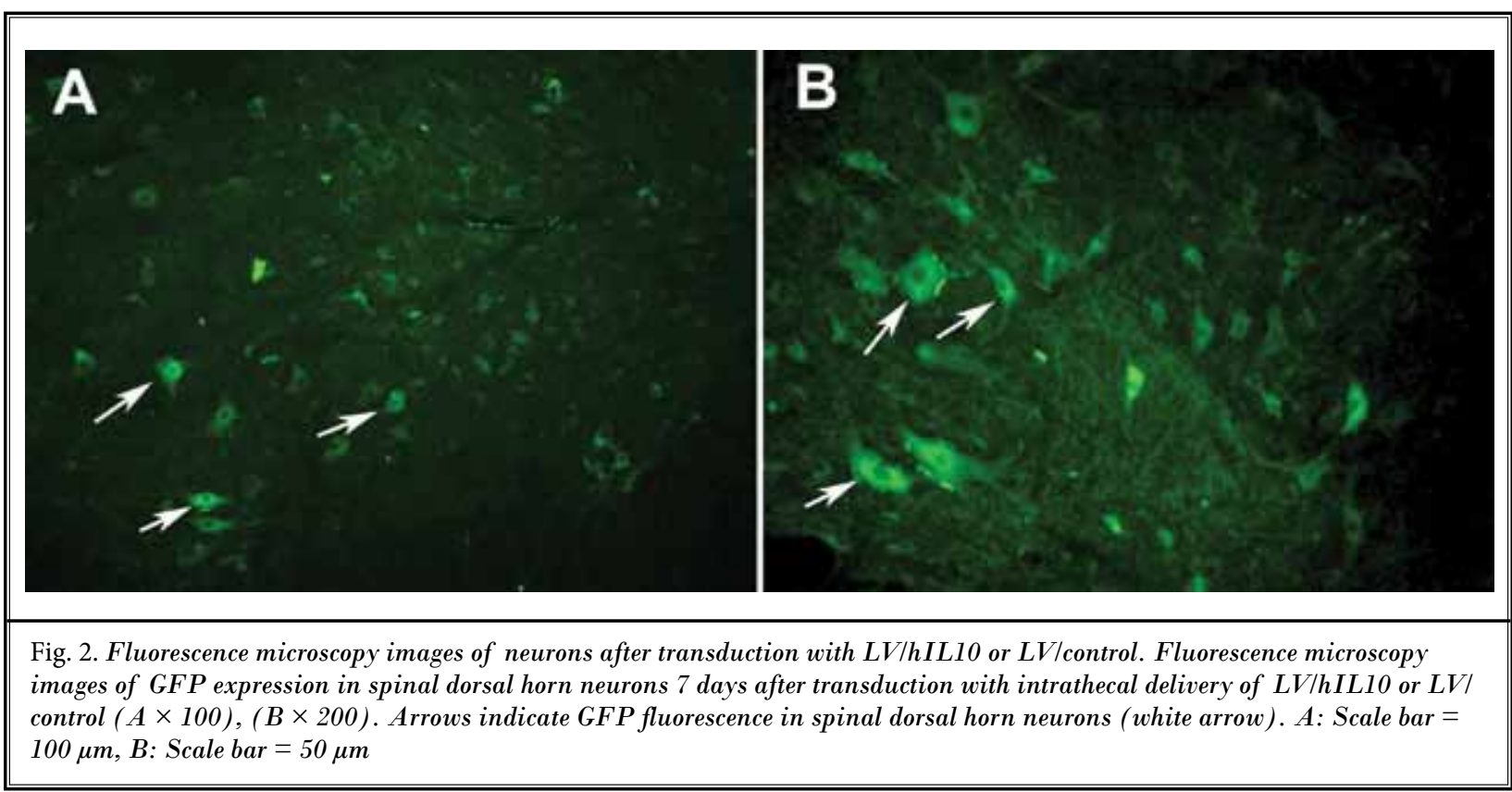




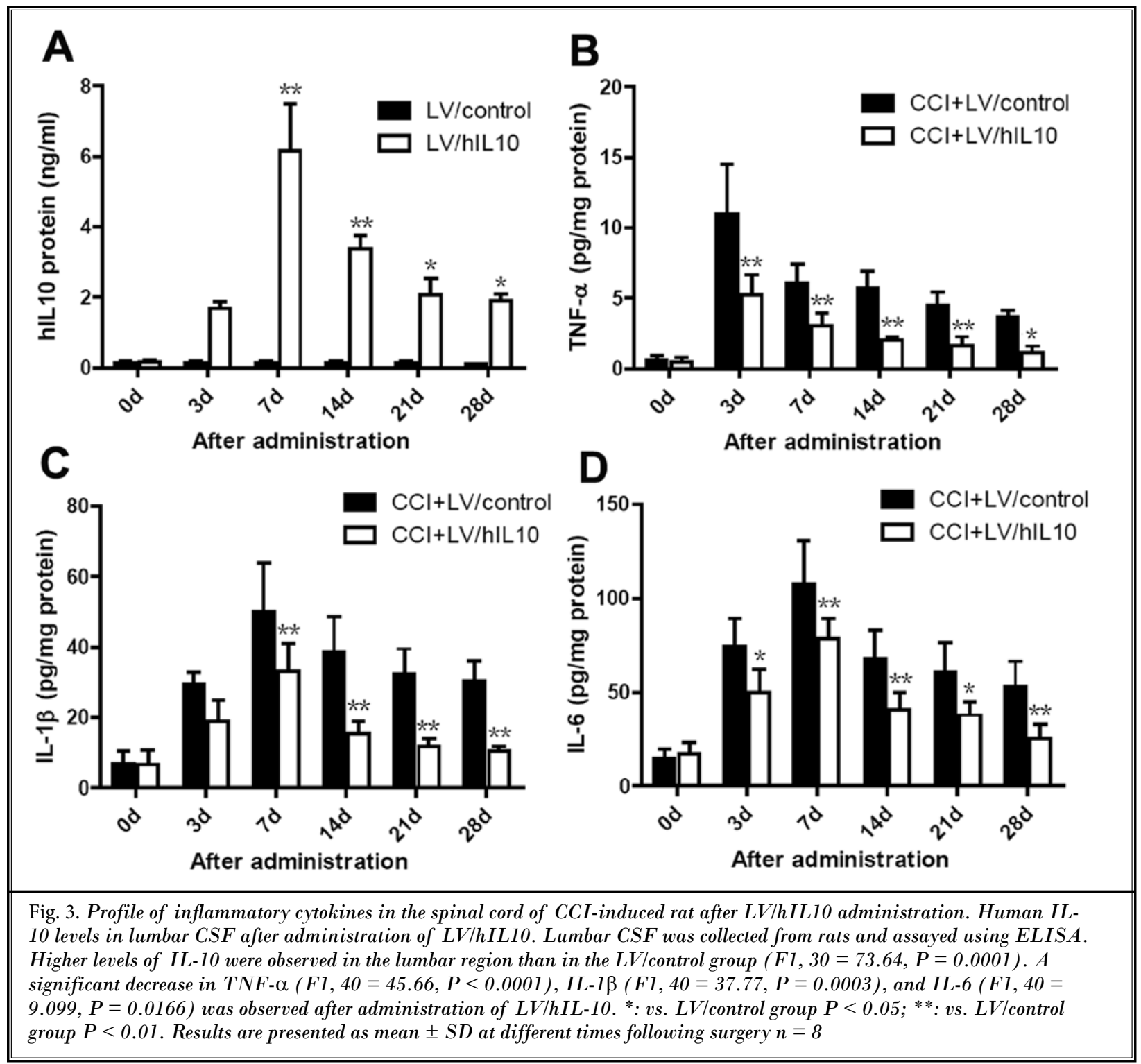

allodynia (F1, $20=86.63, P=0.0007)$ and thermal hyperalgesia of the ipsilateral hindpaw $(F 1,20=71.32, P$ $=0.0011)$, but also $(\mathrm{Cl}$-induced contralateral allodynia (F1, $20=38.32, P=0.035$ ) (Fig. 5A, 5B, 5C).

\section{Effects of Intrathecal Administration of LV/ hIL-10 on Activation of the Spinal HMGB1}

HMGB1 has been shown to increase in rats that suffer from bone cancer pain (14). We detected the expression of HMGB1 in the spinal cords of CCl-induced neuropathic rats. The expression of HMGB1 over time was evaluated in the spinal cords of rats that had been subjected to $\mathrm{CCl}$. Western blot results showed that the HMGB1 expression was up-regulated from day 7 to day 28 in $\mathrm{CCl}$-induced neuropathic pain rats (Fig. 4A) but not in the control or sham rats. We then assessed the expression of HMGB1 lumbar segments of the spinal cord in rats 14 days after the intrathecal administration of LV/hIL-10. Compared to LV/control group and saline group, there was a significant decrease of HMGB1 expression after treatment with LV/hIL10 $(P=0.027, P=$ 0.031 , Fig. $4 B$ and $C$ ). The number of spinal cord cells 


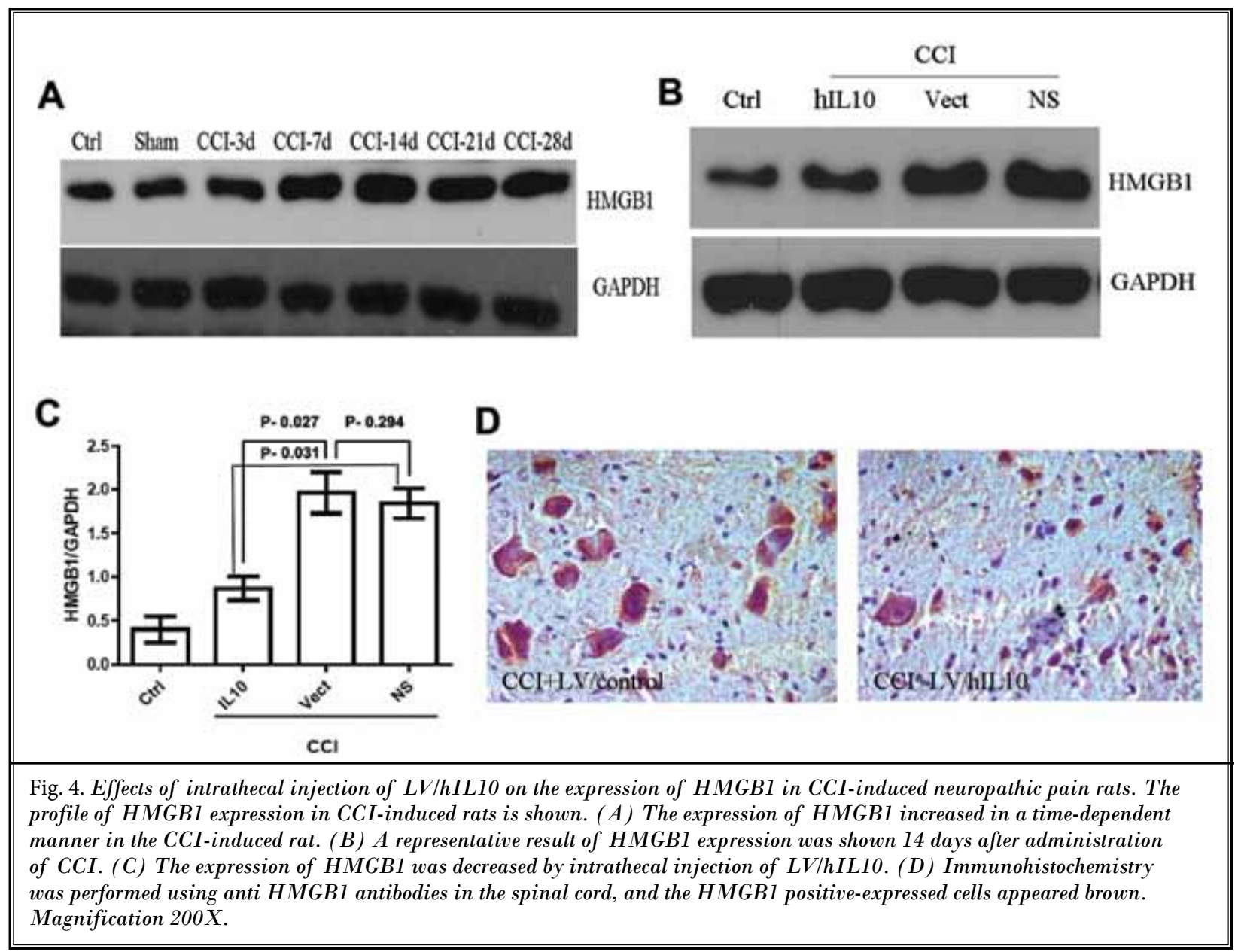

positive for HMGB1 expression was lower in the LV/hIL10 treated rats than in LV/control treated rats (Fig. 4D). To confirm that the activation of HMGB1 was affected by intrathecal administration of LV/hIL-10, the relative expression of $\mathrm{HMGB} 1$, its binding receptor RAGE, and downstream gene were analyzed in the spinal cord of rats 14 days after $\mathrm{CCl}$-induced neuropathic pain. Our results showed that HMGB1, RAGE, and phosphorylated Akt (pAkt) were significantly upregulated in the $\mathrm{CCl}$-treated rats. The expression of HMGB1, pAkt, and its receptors RAGE all were decreased after LV/hIL-10 treatment (Fig. 6A and B).

\section{Discussion}

This study demonstrates that intrathecal administration LV-mediated overexpression of IL-10 has a considerable antinociceptive therapeutic effect and that it exerts this effect through modulation of spinal HMGB1 in rats. To the best of our knowledge, this represents the first demonstration of intrathecal LV-mediated transfer of IL-10 that effectively attenuates $\mathrm{CCl}$-induced neuropathic pain in rats.

This study showed that the occurrence of neuropathic pain was indirectly related to the release of earlier period mediators of inflammation, and the symptoms of neuropathic pain was prolonged. We observed an increase in spinal TNF- $\alpha$, IL-1 $\beta$, and IL- 6 in $\mathrm{CCl}$-induced neuropathic pain rats. The release of earlier period mediators of inflammation, however, was not entirely consistent with the profile of thermal hyperalgesia and mechanical allodynia observed in the $\mathrm{CCl}$-induced neuropathic pain model. One recent study showed that the induction of HMGB1 in the DRG contributes to pain hypersensitivity and that blocking spinal HMGB1 could reverse bone cancer pain by downregulating IL-1 $\beta$ expression (14).

HMGB1 is a ubiquitous nuclear protein that exerts numerous extranuclear and extracellular functions, in- 
cluding proinflammatory activity. It can induce cytokine expression and activate inflammatory cells (39). The relationship between HMGB1 and inflammatory reactions has attracted broad attention, and increasing evidence shows that HMGB1 is the advanced stage at which the

A

IPSILATERAL HIND PAW(Left)

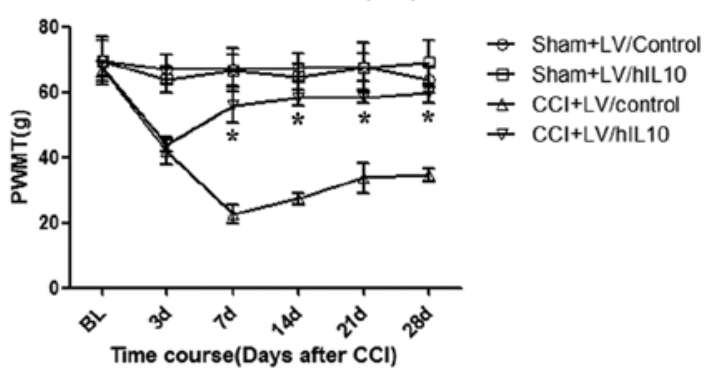

B

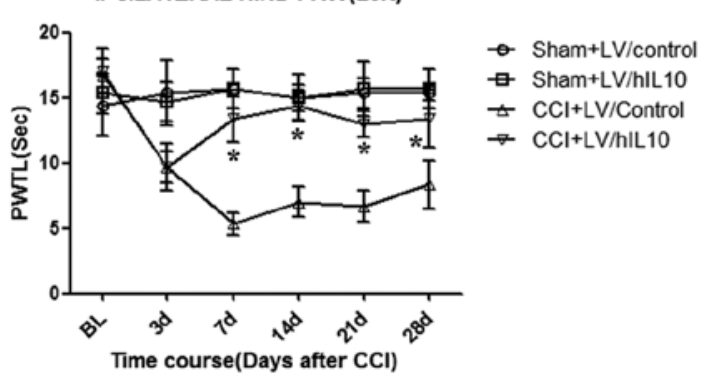

C CONTRALATERAL HINDPAW(Right)

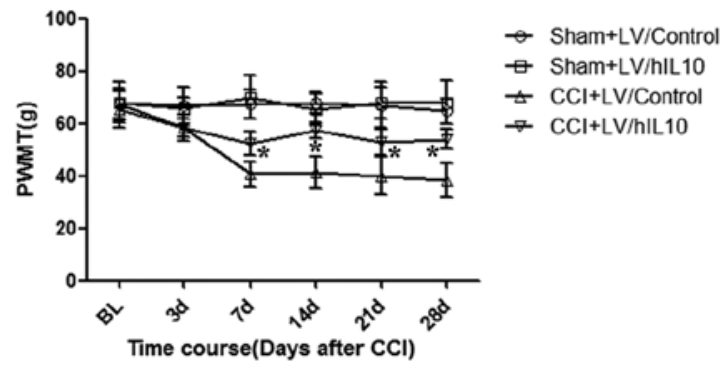

Fig. 5. CCI-induced mechanical allodynia and thermal hyperalgesia over time in rats given CCI and treated with LV/hIL-10. Intrathecal injection of LV/hIL10 significantly reversed (A) CCI-induced mechanical allodynia, (B) thermal hyperalgesia, and $(C)$ contralateral allodynia. Results are presented as mean \pm $S D$ at different times following surgery $n=8$. mediated factor leads to a fatal systemic inflammatory response in sepsis and serious trauma (40). Some studies have indicated that HMGB1 may participate in the invasion procedure of arthritis deformans. HMGB1 is secreted by macrophages, monocytes, and pituicytes after stimulation with endotoxins, LPS, IL-1, TNF- $\alpha$, IFN- $\gamma$, and HGMB1 itself (41). Secretion of HMGB1 can activate these cells, resulting in the release of proinflammatory cytokines, such as TNF- $\alpha, \mathrm{IL}-1 \alpha, \mathrm{IL}-1 \beta, \mathrm{IL}-6$, and IL-8, which are associated with hyperalgesia and mechanical allodynia in $\mathrm{CCl}$ rats (42).

The anti-inflammatory cytokine IL-10 inhibits the production of many different inflammatory mediators. It shows promise as a therapeutic agent for a variety of inflammatory diseases. Because IL-10 has a very short half-life (about 2 h) in rat CSF, IL-10 gene therapy may provide a more efficient means of attaining neuropathic pain control than the use of raw IL-10 (15). LV vectors are among the most popular vectors used for gene delivery into the CNS because they do not initiate the immunological responses that can inhibit the viability of transduced cells and transduce non-proliferating cells (43).

Our results show increased expression of HMGB1 at advanced stages of $\mathrm{CCl}$ in a rat model. This is consistent with the results of other studies $(14,27)$. These data indicate that HMGB1 may affect the occurrence and maintenance of neuropathic pain. In this study, our results also show that intrathecal administration LV/hIL-10 can reverse enhanced pain states. The work provides evidence that intrathecal gene therapy can be used to express anti-inflammatory cytokines, such as IL-10. This may be an approach worthy to be pursued as the treatment for chronic pain, consistent with work done on activated macrophages (44). It was found that there is a notable analgesic effect of IL-10; the mechanism is related to the inhibition of earlier period mediators of the expression of inflammation $(15,45)$. Our work has shown that intrathecal administration of LV/hIL-10 can exert an analgesic effect and inhibit the expression of advanced-stage mediators of inflammation, such as HMGB1. Downregulated expression of HMGB1 may participate in the analgesic mechanism of IL-10. HMGB1 has been shown to transduce cellular signals by interacting with RAGE. This leads to activation of the nuclear factor pathway, which promotes cytokine production (46). Our results have shown that IL-10 inhibits activation of the HMGB1-RAGE pathway, which increases the concentration of inflammatory cytokines in $\mathrm{CCl}$ rats. More 


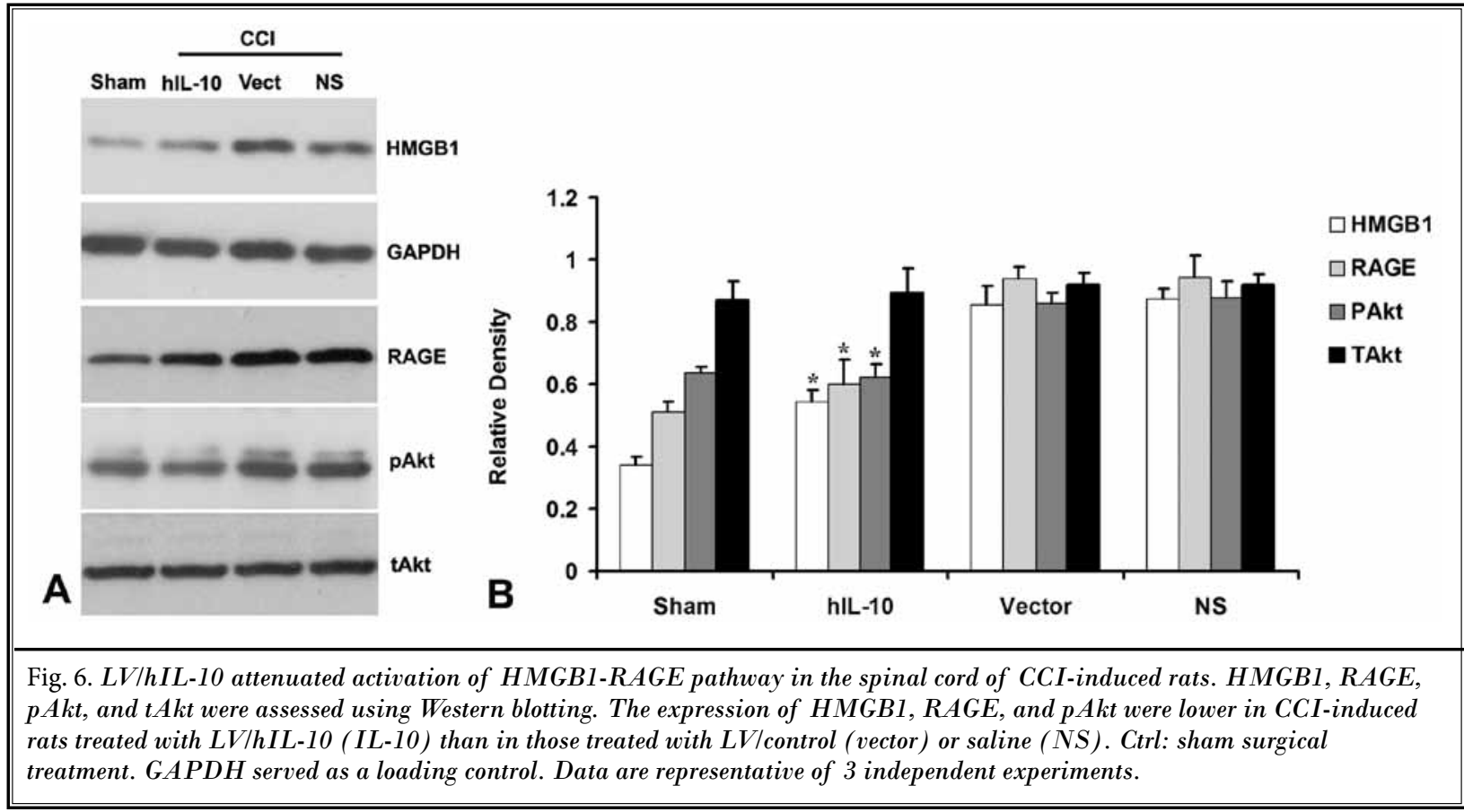

research is needed to determine how $\mathrm{IL}-10$ interacts with HMGB1 and participates in the maintenance of neuropathic pain and its analgesic mechanism.

This study confirms that LV/hIL10 can reverse thermal hyperalgesia and mechanical allodynia in $\mathrm{CCl}$ rats and that these effects may be partially due to the decreased expression of HMGB1 and inhibition of the HMGB1-RAGE pathway. These findings may have implications for future study designs and therapeutic approaches to management of neuropathic pain.

\section{Strengths and Limitations}

The current study reports the first proof that intrathecal LV-mediated transfer of IL-10 can attenuate $\mathrm{CCl}$-induced neuropathic pain in rats. Intrathecal LVmediated overexpression of IL-10 provides a prolonged antinociceptive therapeutic effect through modulation of spinal HMGB1 in $\mathrm{CCl}$ rats. There could be several limitations in the current study. Firstly, further experimental investigations utilizing HMGB1 gene knock-out models or glycyrrhizin, a known inhibitor of HMGB1, are needed to clarify the specific biological roles played by HMGB1 in IL-10-mediated regulation of neuropathic pain. In addition, more LV/hIL-10 doses should be used to further investigate the dose-effect relationship in the future.

\section{Acknowledgments}

Dr. He and Dr. Guo contributed equally to this work.

This work was supported by grants from the National Natural Science Foundation of China (Nos. 81271244 and 81171053) and Young Investigator Development Program of Central South University (awarded to WZ).

\section{References}

1. Zimmermann M. Pathobiology of neuropathic pain. Eur J Pharmacol 2001; 429:23-37.

2. Lyon RM, Clarke S, Milligan D, Clegg GR. Resuscitation feedback and targeted education improves quality of pre-hospital resuscitation in Scotland. Resuscitation 2012; 83:70-75.

3. Watkins LR, Maier SF. Glia: A novel drug discovery target for clinical pain. Nat Rev
Drug Discov 2003; 2:973-985.

4. Watkins LR, Milligan ED, Maier SF. Glial activation: A driving force for pathological pain. Trends Neurosci 2001; 24:450-455.

5. Gao YJ, Ji RR. Chemokines, neuronal-glial interactions, and central processing of neuropathic pain. Pharmacology \& Therapeutics 2010; 126:56-68

6. Schoeniger-Skinner DK, Ledeboer A, Frank MG, Milligan ED, Poole S, Martin
D, Maier SF, Watkins LR. Interleukin-6 mediates low-threshold mechanical allodynia induced by intrathecal HIV-ı envelope glycoprotein gpı2o. Brain Behav Immun 2007; 21:660-667.

7. Leung L, Cahill CM. TNF-alpha and neuropathic pain--a review. Journal of Neuroinflammation 2010; 7:27.

8. Ren K, Torres R. Role of interleukin-ıbeta during pain and inflammation. Brain 
Research Reviews 2009; 60:57-64.

9. He Z, Xiao M, Guo Q. IL-10 overexpression attenuated expression of TNF-alpha and IL-ibeta activated by lipopolysaccharide in astrocytes. Zhong nan da xue xue bao Yi xue ban = journal of Central South University Medical Sciences 2011; 36:392-397.

10. Milligan DJ, Fields AM. Levosimendan: Calcium sensitizer and inodilator. Anesthesiology Clinics 2010; 28:753-760.

11. Bucciarelli LG, Wendt T, Rong L, Lalla E, Hofmann MA, Goova MT, Taguchi A, Yan SF, Yan SD, Stern DM, Schmidt AM. RAGE is a multiligand receptor of the immunoglobulin superfamily: Implications for homeostasis and chronic disease. Cell Mol Life Sci 2002; 59:1117-1128.

12. Kuniyasu H, Yano S, Sasaki T, Sasahira T, Sone S, Ohmori H. Colon cancer cell-derived high mobility group $1 / a m$ photerin induces growth inhibition and apoptosis in macrophages. The American Journal of Pathology 2005; 166:751-760.

13. Wagner R, Janjigian M, Myers RR. Antiinflammatory interleukin-10 therapy in $\mathrm{CCl}$ neuropathy decreases thermal hyperalgesia, macrophage recruitment, and endoneurial TNF-alpha expression. Pain 1998; 74:35-42.

14. Tong W, Wang W, Huang J, Ren N, Wu SX, Li YQ. Spinal high-mobility group box 1 contributes to mechanical allodynia in a rat model of bone cancer pain. Biochemical and Biophysical Research Communications 2010; 395:572-576.

15. Milligan J, Lee J, McMillan C, Klassen $\mathrm{H}$. Autonomic dysreflexia: Recognizing a common serious condition in patients with spinal cord injury. Canadian Family Physician Medecin de Famille Canadien 2012; 58:831-835.

16. Milligan ED, Langer SJ, Sloane EM, He L, Wieseler-Frank J, O'Connor K, Martin D, Forsayeth JR, Maier SF, Johnson K, Chavez RA, Leinwand LA, Watkins LR. Controlling pathological pain by adenovirally driven spinal production of the anti-inflammatory cytokine, interleukin-10. The European Journal of Neuroscience 2005; 21:2136-2148.

17. Milligan ED, Sloane EM, Langer SJ, Cruz PE, Chacur M, Spataro L, WieselerFrank J, Hammack SE, Maier SF, Flotte TR, Forsayeth JR, Leinwand LA, Chavez $R$, Watkins LR. Controlling neuropathic pain by adeno-associated virus driven production of the anti-inflammatory cytokine, interleukin-10. Molecular Pain
2005; 1:9.

18. Baekelandt $\mathrm{V}$, Eggermont $\mathrm{K}$, Michiels $\mathrm{M}$, Nuttin B, Debyser Z. Optimized lentiviral vector production and purification procedure prevents immune response after transduction of mouse brain. Gene Ther 2003; 10:1933-1940.

19. Andrews PJ, Avenell A, Noble DW, Campbell MK, Croal BL, Simpson WG, Vale LD, Battison CG, Jenkinson DJ, Cook JA. Randomised trial of glutamine, selenium, or both, to supplement parenteral nutrition for critically ill patients. BM] 2011; 342:d1542.

20. Snodgrass J. Effective occupational therapy interventions in the rehabilitation of individuals with work-related low back injuries and illnesses: A systematic review. The American Journal of Occupational Therapy: Official Publication of the American Occupational Therapy Association 2011; 65:37-43.

21. Lundberg C, Bjorklund T, Carlsson T, Jakobsson J, Hantraye P, Deglon N, Kirik D. Applications of lentiviral vectors for biology and gene therapy of neurological disorders. Curr Gene Ther 2008; 8:461-473.

22. Annoni A, Goudy K, Akbarpour M, NaIdini L, Roncarolo MG. Immune responses in liver-directed lentiviral gene therapy. Translational Research: The Journal of Laboratory and Clinical Medicine 2013. \{need issue and pages\}

23. Zou W, Song Z, Guo Q, Liu C, Zhang Z, Zhang Y. Intrathecal lentiviral-mediated RNA interference targeting PKCgamma attenuates chronic constriction injuryinduced neuropathic pain in rats. Hum Gene Ther 2011; 22:465-475.

24. Song Z, Zou W, Liu C, Guo Q. Gene knockdown with lentiviral vector-mediated intrathecal RNA interference of protein kinase $\mathrm{C}$ gamma reverses chronic morphine tolerance in rats. The Journal of Gene Medicine 2010; 12:873-880.

25. van Strien ME, Mercier D, Drukarch B, Breve JJ, Poole S, Binnekade R, Bol JG, Blits B, Verhaagen J, van Dam AM. Anti-inflammatory effect by lentiviralmediated overexpression of IL-10 or IL-1 receptor antagonist in rat glial cells and macrophages. Gene Therapy 2010; 17:662-671.

26. Sims GP, Rowe DC, Rietdijk ST, Herbst R, Coyle AJ. HMGBi and RAGE in inflammation and cancer. Annual Review of Immunology 2010; 28:367-388.

27. Shibasaki M, Sasaki M, Miura M, Mizu- koshi K, Ueno H, Hashimoto S, Tanaka $Y$, Amaya F. Induction of high mobility group box-1 in dorsal root ganglion contributes to pain hypersensitivity after peripheral nerve injury. Pain 2010; 149:514-521.

28. Feldman P, Due MR, Ripsch MS, Khanna $R$, White FA. The persistent release of $\mathrm{HMGB}$ contributes to tactile hyperalgesia in a rodent model of neuropathic pain. Journal of Neuroinflammation 2012; 9:180.

29. Kuang $X$, Huang Y, Gu HF, Zu XY, Zou WY, Song ZB, Guo QL. Effects of intrathecal epigallocatechin gallate, an inhibitor of Toll-like receptor 4 , on chronic neuropathic pain in rats. Eur] Pharmacol 2012; 676:51-56.

30. Milligan ED, Sloane EM, Langer SJ, Hughes TS, Jekich BM, Frank MG, Mahoney JH, Levkoff LH, Maier SF, Cruz PE, Flotte TR, Johnson KW, Mahoney MM, Chavez RA, Leinwand LA, Watkins LR. Repeated intrathecal injections of plasmid DNA encoding interleukin-10 produce prolonged reversal of neuropathic pain. Pain 2006; 126:294-308.

31. Milligan ED, Penzkover KR, Soderquist RG, Mahoney MJ. Spinal interleukin-10 therapy to treat peripheral neuropathic pain. Neuromodulation: journal of the International Neuromodulation Society 2012; 15:520-526.

32. Bennett GJ, Xie YK. A peripheral mononeuropathy in rat that produces disorders of pain sensation like those seen in man. Pain 1988; 33:87-107.

33. Zimmermann $M$. Ethical guidelines for investigations of experimental pain in conscious animals. Pain 1983; 16:109-110.

34. Malkmus SA, Yaksh TL. Intrathecal catheterization and drug delivery in the rat. Methods Mol Med 2004; 99:109-121.

35. Hargreaves K, Dubner R, Brown F, Flores $\mathrm{C}$, Joris J. A new and sensitive method for measuring thermal nociception in cutaneous hyperalgesia. Pain 1988; 32:77-88.

36. Chaplan SR, Bach FW, Pogrel JW, Chung JM, Yaksh TL. Quantitative assessment of tactile allodynia in the rat paw. J Neurosci Methods 1994; 53:55-63.

37. Florijn RJ, Slats J, Tanke HJ, Raap AK. Analysis of antifading reagents for fluorescence microscopy. Cytometry 1995; 19:177-182.

38. Murua Escobar H, Meyer B, Richter A, 
Becker K, Flohr AM, Bullerdiek J, Nolte I. Molecular characterization of the canine HMGB1. Cytogenetic and Genome Research 2003; 101:33-38.

39. Scaffidi P, Misteli T, Bianchi ME. Release of chromatin protein $\mathrm{HMGB}$ by necrotic cells triggers inflammation. $\mathrm{Na}$ ture 2002; 418:191-195.

40. Wang H, Yang H, Tracey KJ. Extracellular role of $\mathrm{HMGB} 1$ in inflammation and sepsis. J Intern Med 2004; 255:320-331.

41. Park JS, Arcaroli J, Yum HK, Yang H, Wang $\mathrm{H}$, Yang KY, Choe KH, Strassheim D, Pitts TM, Tracey KJ, Abraham E. Activation of gene expression in human neutrophils by high mobility group box 1 protein. Am J Physiol Cell Physiol 2003; 284:C870-879.

42. Lawrence $S$, Willmott L, Milligan E, Winch S, White B, Parker M. Autonomy versus futility? Barriers to good clinical practice in end-of-life care: A Queensland case. The Medical Journal of Australia 2012; 196:404-405.

43. Amado RG, Chen IS. Lentiviral vectors-the promise of gene therapy within reach? Science 1999; 285:674-676.

44. Donnelly RP, Dickensheets H, Finbloom DS. The interleukin-1o signal transduction pathway and regulation of gene ex- pression in mononuclear phagocytes. J Interferon Cytokine Res 1999; 19:563-573.

45. Yu CG, Fairbanks CA, Wilcox GL, Yezierski RP. Effects of agmatine, interleukin-10, and cyclosporin on spontaneous pain behavior after excitotoxic spinal cord injury in rats. J Pain 2003; 4:129-140.

46. Park JS, Svetkauskaite D, He Q, Kim JY, Strassheim D, Ishizaka A, Abraham E. Involvement of toll-like receptors 2 and 4 in cellular activation by high mobility group box 1 protein. J Biol Chem 2004; 279:7370-7377. 
